\title{
University students' alcohol use behaviour and self-efficacy to abstain from alcohol use: data from Ghana
}

\author{
Franklin N. Glozah ${ }^{* *}$ (1) and Joyce Komesuor ${ }^{2}$
}

\begin{abstract}
Objectives: The university students'alcohol use behaviour and alcohol use self-efficacy data were collected among Ghanaian university students. This survey had two main objectives: (a) to examine the factorial validity, structure, and reliability of the 20-item alcohol abstinence self-efficacy scale among undergraduate students and (b) to examine the role of alcohol abstinence self-efficacy in the pros and cons of alcohol use. These two objectives have been published as separate research articles without the data (including data management) that were used for analyses. As the data are not already available as part of these published papers, this data note provides a composite and integrated data grounded on these published research articles with detailed information on the instruments used to collect data, raw data in statistical software, managed/coded data in statistical software, and generated correlation matrix used to perform complex analysis.

Data description: The data includes information on two major dimensions: (a) alcohol abstinence self-efficacynegative affect, social interactions and positive states, physical pain/illness, and alcohol craving (thoughts about using) and (b) decisional balance-measuring the benefits (pros) of alcohol use and the costs (cons) of alcohol use. In addition, data were collected on socio-demographic characteristics of students including their age, sex, level/year in school, stream of study, place of residence and religious affiliation. The data collected is more representative of students in private universities.
\end{abstract}

Keywords: Alcohol use, Alcohol use self-efficacy, Psychometrics, Ghana, University students

\section{Objective}

There is an increasing awareness of indiscriminate alcohol use among University students world-wide. Selfefficacy to abstain from alcohol use is known to play a significant role in alcohol use abstinence by perceiving fewer benefits (pros) and perceiving more costs (cons) in alcohol use. However, not much is known about selfefficacy to abstain from alcohol use in relation to the pros and cons of alcohol use among Ghanaian university students. This survey had to main objectives: (a) to examine the factorial validity, structure, and reliability of the 20-item alcohol abstinence self-efficacy scale in

\footnotetext{
*Correspondence: fglozah@ug.edu.gh

${ }^{1}$ Department of Social and Behavioural Sciences, School of Public Health, University of Ghana, Accra, Ghana

Full list of author information is available at the end of the article
}

undergraduate students and (b) to examine the role of alcohol abstinence self-efficacy in the pros and cons of alcohol use. The survey was conducted due, primarily, to the fact that there is a paucity of research literature documenting alcohol use behaviour and alcohol abstinence self-efficacy in Ghanaian university students. Two major publications have resulted from these two main objectives. These are [1] that examined the factorial validity, structure, and reliability of the 20-item alcohol abstinence self-efficacy scale in undergraduate students and [2] that examined the role of alcohol abstinence self-efficacy in the pros and cons of alcohol use in undergraduate students. As the data are not already available as part of these published papers, this data note provides a composite and integrated data grounded on these published research articles with detailed information on the instruments used to collect data, raw data in statistical 
Table 1 Overview of data files

\begin{tabular}{llll}
\hline Label & Name of data file & $\begin{array}{l}\text { File types } \\
\text { (file extension) }\end{array}$ & Data repository and identifier (DOI or accession number) \\
\hline Data set 1 & Correlation matrix & AASESmx.tab & Harvard Dataverse (https://doi.org/10.7910/DVN/6R4DOG) [5] \\
Data set 2 & SPSS raw data & Raw.tab & Harvard Dataverse (https://doi.org/10.7910/DVN/6R4DOG) [5] \\
Data set 3 & SPSS coded data & Scales.tab & Harvard Dataverse (https://doi.org/10.7910/DVN/6R4DOG) [5] \\
Data file 1 & Questionnaire & Research Questionnaire.pdf & Harvard Dataverse (https://doi.org/10.7910/DVN/6R4DOG) [5] \\
\hline
\end{tabular}

software, managed/coded data in statistical software, and generated correlation matrix used to perform complex analysis. Furthermore, this data note is meant to serve as benchmark data particularly for Ghana and Sub-Saharan Africa in general, due to the paucity of research literature and data documenting alcohol use behaviour and alcohol abstinence self-efficacy among university students within these contexts.

\section{Data description}

The data handling was identical to our publication [1] from 2015 that consisted of 215 undergraduate students from a population of about 2000 students in a private university in Ghana. A simple random sampling method was used to select a few classes from various programs. All participants gave a written informed consent before participating in the study.

In addition to pertinent socio-demographic characteristics, two main instruments were used for data collection-the alcohol abstinence self-efficacy scale and alcohol decisional balance scale. The alcohol abstinence self-efficacy scale [3] assesses self-efficacy and evaluates an individual's efficacy to abstain from drinking in 20 situations that represent typical drinking cues. Like our 2015 publication [1], participants were asked to give a current estimate of their efficacy to abstain from alcohol. These situations constituted four sub-scales and are rated on a 5-point Likert scale, where higher scores indicate higher self-efficacy to abstain from alcohol use.

The alcohol decisional balance scale consists of 10 items measuring the benefits (pros) of alcohol use and 10 items measuring the costs (cons) of alcohol use [4]. Participants responded on a 5-point Likert scale ranging from 0-not at all important to 4-extremely important on both the pros and cons subscales with higher scores representing both more pros and cons of drinking alcohol. In populations or cultures with less drinking experience, the measure is commonly construed as an individual's decision making regarding whether or not to drink alcohol at all [4]. Items for both alcohol abstinence self-efficacy scale and alcohol decisional balance scale are available on Harvard dataverse [5]. Table 1 contains a link to Harvard dataverse (Data file 1) where the questionnaire used for data collection could be retrieved.

In addition, Table 1 contains information about the raw data (Data set 2)-data entered into SPSS directly from completed questionnaires, and coded data (Data set 3)-data in SPSS with various scales and subscales created. Furthermore, Table 1 contains information on the correlation matrix (Data set 1) that was generated and used in AMOS software to perform structural equation modelling to examine the factorial validity of the instruments. A correlation matrix shows correlation coefficients between variables of interest-each cell in the table (Data set 1 ) shows the correlation between two variables, used to summarize a large dataset for further statistical analysis.

\section{Limitations}

First, a relatively small sample size was used in this survey so generalizing the data (collected from students in a single private university) to the whole of Ghana should be done with caution. However, although the sample size was relatively small, power analysis for a MANCOVA with eight groups, four predictors and two dependent variables conducted in G-POWER [6] to determine a sufficient sample size using an alpha of 0.05 , a power of 0.90 , and a small effect size of 0.10 produced a desired sample size of 100, suggesting that the use of 215 participants has most likely produced quality data. Secondly, there were more non-drinkers compare to drinkers in the sample and this could have biased the significance of the findings. Finally, the questionnaires only gathered data with respect to normal alcohol use-the results could have been different if data had been gathered on heavy alcohol use among university students.

\section{Abbreviations}

AASES: alcohol abstinence self-efficacy scale; ADBS: alcohol decisional balance scale.

\section{Acknowledgements}

We would like to thank Nana Ama Takyibea Adu, Mariam Akwei and Felix Aggrey for contributing to the survey via data collection and data entry. Also, we are thankful to all the students who participated in the study, without their participation and cooperation this study would not have been possible. 


\section{Authors' contributions}

FNG is the principal investigator for the project. He conceptualized the study and performed all statistical analyses. JK participated in literature review and data collection and entry.Both authors contributed to drafting and proofreading the paper. Both authors read and approved the final manuscript.

\section{Funding}

The authors did not receive any funding for the study.

\section{Availability of data materials}

The data described in this Data note can be freely and openly accessed on Harvard Dataverse https://doi.org/10.7910/DVN/6R4DOG. Please see Table 1 and reference list for details and links to the data.

\section{Ethics approval and consent to participate}

The Ethics and Research Committee of Regent University gave formal permission and ethical approval (GSR/EA/14/003) for the study to be conducted. Written informed consent to participate in the survey was obtained in order to safeguard the right and autonomy of the participants.

\section{Consent for publication}

Not Applicable.

\section{Competing interests}

The authors declare that they have no competing interests.

\section{Author details}

1 Department of Social and Behavioural Sciences, School of Public Health, University of Ghana, Accra, Ghana. ${ }^{2}$ Department of Population and Behavioural Sciences, School of Public Health, University of Health and Allied Sciences, Ho, Ghana.
Received: 16 April 2019 Accepted: 3 October 2019

Published online: 16 October 2019

\section{References}

1. Glozah FN, Adu NAT, Komesuor J. Assessing alcohol abstinence self-efficacy in undergraduate students: psychometric evaluation of the alcohol abstinence self-efficacy scale. Health Qual Life Outcomes. 2015;13:189. https://doi.org/10.1186/s12955-015-0387-1.

2. Glozah FN, Komesuor J, Adu NAT, Aggrey FK. The role of alcohol abstinence self-efficacy in the pros and cons of alcohol use: a cross-sectional survey of Ghanaian undergraduate students. Afr J Drug Alcohol Stud. 2017;16:11-22

3. DiClemente CC, Carbonari JP, Montgomery RPG, Hughes SO. The alcohol abstinence self-efficacy scale. J Stud Alcohol Drugs. 1994;55:141-8.

4. Migneault JP, Velicer WF, Prochaska JO, Stevenson JF. Decisional balance for immoderate drinking in college students. Subst Use Misuse. 1999;34:1325-46.

5. Glozah F. Replication Data for Ghana university students' alcohol use behaviour. Harvard Dataverse. 2019. https://doi.org/10.7910/DVN/6R4DOG

6. Faul F, Erdfelder E, Buchner A, Lang A-G. Statistical power analyses using G*Power 3.1: Tests for correlation and regression analyses. Behav Res Methods. 2009:41:1149-60.

\section{Publisher's Note}

Springer Nature remains neutral with regard to jurisdictional claims in published maps and institutional affiliations.
Ready to submit your research? Choose BMC and benefit from:

- fast, convenient online submission

- thorough peer review by experienced researchers in your field

- rapid publication on acceptance

- support for research data, including large and complex data types

- gold Open Access which fosters wider collaboration and increased citations

- maximum visibility for your research: over 100M website views per year

At BMC, research is always in progress.

Learn more biomedcentral.com/submissions 